\title{
Do post-migration perceptions of social mobility matter for Latino immigrant health?
}

\author{
Carmela Alcántara ${ }^{a, b,{ }^{*},}$ Chih-Nan Chen ${ }^{c}$, and Margarita Alegría ${ }^{d}$ \\ aHarvard University, USA \\ ${ }^{b}$ Columbia University, USA \\ 'National Taipei University, Taiwan \\ dHarvard Medical School, USA
}

\begin{abstract}
Latino immigrants exhibit health declines with increasing duration in the United States, which some attribute to a loss in social status after migration or downward social mobility. Yet, research into the distribution of perceived social mobility and patterned associations to Latino health is sparse, despite extensive research to show that economic and social advancement is a key driver of voluntary migration. We investigated Latino immigrant sub-ethnic group variation in the distribution of perceived social mobility, defined as the difference between respondents' perceived social status of origin had they remained in their country of origin and their current social status in the U.S. We also examined the association between perceived social mobility and past-year major depressive episode (MDE) and self-rated fair/poor physical health, and whether Latino subethnicity moderated these associations. We computed weighted logistic regression analyses using subsample ( $N=1561$ the Latino immigrant) of the National Latino and Asian American Study. Puerto Rican migrants were more likely to perceive downward social mobility relative to Mexican and Cuban immigrants who were more likely to perceive upward social mobility. Perceived downward social mobility was associated with increased odds of fair/poor physical health and MDE. Latino sub-ethnicity was a statistically significant moderator, such that perceived downward social mobility was associated with higher odds of MDE only among Puerto Rican and Other Latino immigrants. In contrast, perceived upward social mobility was not associated with self-rated fair/poor physical health. Our findings suggest that perceived downward social mobility might be an independent correlate of health among Latino immigrants, and might help explain Latino sub-ethnic group differences in mental health status. Future studies on Latino immigrant health should use prospective designs to examine the physiological and psychological costs associated with perceived changes in social status with integration into the U.S. mainland.
\end{abstract}

\footnotetext{
(C) 2013 Elsevier Ltd. All rights reserved.

*Corresponding author. Center for Behavioral Cardiovascular Health, Department of Medicine, Columbia University Medical Center, PH-9, Room 9-319, 622 West 168th Street, New York, NY 10032, USA. Fax: +1 212342 3431. ca2543@ columbia.edu (C. Alcántara).
} 


\section{Keywords}

USA; Hispanic; Major depressive episode; Physical health; Socioeconomic status; Subjective social status; Immigrants; Health disparities

\section{Introduction}

Latino immigrants exhibit lower if not equal rates of physical diseases and psychiatric disorders relative to their non-Latino White counterparts in the United States (U.S.), yet have more disadvantaged socioeconomic profiles and disproportionately concentrate in under-resourced communities (Abraido-Lanza, Dohrenwend, Ng-Mak, \& Turner, 1999; Alegría et al., 2008; Bates, Acevedo-Garcia, Alegría, \& Krieger, 2008; Sorlie, Backlund, Johnson, \& Rogot, 1993). These health advantages decline over time and across subsequent generations, with the strongest and most consistent support for this trend observed among Mexicans (Alegría et al., 2008; Alegría, Sribney, Woo, Torres, \& Guarnaccia, 2007; Palloni \& Arias, 2004; Vega et al., 1998). Some have attributed the increased psychiatric and physical health risks associated with longer duration in the U.S. to the consequences of cumulative exposure to social disadvantage broadly (Cook, Alegría, Lin, \& Guo, 2009), and in some instances, to the loss of social status as a function of migration (Alegria, 2009). However, few investigations examine the distribution of social mobility-the upward, horizontal, or downward movement in the socioeconomic hierarchy (Müller, 2001) —and its associated health consequences among Latino immigrants who might experience or perceive dramatic changes in their relative socioeconomic status (SES) and their relative social status with migration to the U.S. mainland.

\section{Background on immigration, social mobility, and social status}

\section{Psychology of contemporary immigration}

Immigration is often the consequence of economic, social, and political factors that push or pull individuals to migrate across nation states (Portes \& Rumbaut, 2006). For example, immigration often occurs for social and economic advancement (social mobility), family reunification, or to escape persecution and find refuge. With regard to social and economic advancement, scholars of contemporary immigration posit that in today's increasingly globalized world psychological factors focused on perceptions of relative status and relative deprivation also shape economic decisions to migrate (American Psychological Association, 2012; Mahalingam, 2006; Portes \& Rumbaut, 2006; Stark \& Bloom, 1985). For example, immigrants, especially voluntary immigrants, often weigh their desire to fulfill economic and career aspirations against their perceived chances for success in their sending countries given the available salaries and work context (Portes \& Rumbaut, 2006). If an individual perceives an unfavorable imbalance between aspirations and life chances in the home country, he or she will decide to migrate (Portes \& Rumbaut, 2006). Thus, those who migrate voluntarily often evaluate their perceived relative social status in their sending country if they were to stay, against their projected relative social status in the receiving country, and migrate most often when the probability of upward social mobility with migration is higher than with non-migration (Portes \& Rumbaut, 2006). From this 
perspective, evaluations of the potential for upward shifts in social status are central to the decision to migrate and remain important after migration. Where an immigrant settles, the modes of incorporation into the U.S. mainland, and the context for migration are also likely to shape individual-level psychological perceptions of relative social status as well as actual socioeconomic trajectories (Chen, Gee, Spencer, Danziger, \& Takeuchi, 2009; Deaux, 2000; Portes \& Zhou, 1993; Stark \& Bloom, 1985; Zhou, 1997).

Research into the health consequences of changes in social status due to migration is virtually nonexistent. By far, more research has focused on the determinants of Latino migration to the United States mainland, finding diverse reasons for migration as a function of sub-ethnicity. While Latinos regardless of sub-ethnic group, identified the need to improve the future of their children as a chief driver to migrate, Mexicans were more likely to report migrating to the U.S. mainland for employment opportunities, and Cubans and Other Latinos were more likely to report migrating to the U.S. mainland for political reasons (Guarnaccia et al., 2007). Overall, most reported some degree of satisfaction with the economic opportunities in the U.S. mainland, with roughly $20 \%$ reporting some degree of dissatisfaction, and differences in the degree of dissatisfaction by sub-ethnicity were also observed (Guarnaccia et al., 2007). These findings suggest that there are significant subgroup differences in the extent to which Latino immigrants' self-report a match between their economic aspirations and their economic success in the U.S. mainland. The extent to which a perceived match or mismatch in social status (in the U.S. mainland and in the country of origin if remained there) - a psychological process-is associated with health is the focus of this investigation.

\section{Objective social mobility and health}

While the best available evidence on the association of change in social status with migration and health comes from research on social mobility, measured objectively, and health, most of this research was conducted outside the U.S. and/or at the exclusion of racial/ethnic minorities and immigrants. Nonetheless, cross-sectional and longitudinal studies using objective indicators of social mobility suggest that downward social mobility relative to no change is associated with a higher likelihood of poor physical health and negative health behaviors (Hallqvist, Lynch, Bartley, Lang, \& Blane, 2004; Harding, 2003; Hart, Smith, \& Blane, 1998; Loucks et al., 2010; Nilsson, Nilsson, Ostergren, \& Berglund, 2005; Rosvall, Chaix, Lynch, Lindstrom, \& Merlo, 2006; Smith et al., 2011; Watt, Carson, Lawlor, Patel, \& Ebrahim, 2009). In contrast, three longitudinal and two cross-sectional studies find upward social mobility decreases the likelihood of poor health outcomes (Chittleborough, Taylor, Baum, \& Hiller, 2009; Cleland, Ball, Magnussen, Dwyer, \& Venn, 2009; Colen, Geronimus, Bound, \& James, 2006; Heller, McElduff, \& Edwards, 2002; Otero-Rodriguez et al., 2010), while one cross-sectional and one longitudinal study find evidence of increased risk of poor health with upward social mobility (Colen et al., 2006; Heraclides \& Brunner, 2010). Still other cross-sectional research does not find a significant main association between upward or downward social mobility and health (Broman, 1989; Pollitt, Rose, \& Kaufman, 2005). 
Even less is known about the association of objective indicators of social mobility with mental health within and outside the U.S. (Das-Munshi, Leavey, Stansfeld, \& Prince, 2011). Findings from cross-sectional and longitudinal research suggest that downward social mobility is associated with poor coping skills, psychiatric disorders such as depression, psychiatric hospitalization, and functional impairment (Das-Munshi et al., 2011; Nicklett \& Burgard, 2009; Tiffin, Pearce, \& Parker, 2005; Timms, 1998). Similar to the literature on social mobility and physical health, upward social mobility was associated with reduced mental health risk in one instance (Timms, 1996), and not statistically related to psychiatric disorder in another instance (Timms, 1998).

In sum, results from cross-sectional and longitudinal research indicate a consistent association between downward social mobility, measured objectively, and poor physical and mental health relative to stable or upward social mobility. Many of the theoretical explanations offered for the adverse association between downward social mobility and health draw from bio-psychosocial models of stress and disease vulnerability (Gallo, Bogart, Vranceanu, \& Matthews, 2005; Gallo \& Matthews, 2003; Geronimus, 1992; McEwen, 1998; Myers, 2009; Wilkinson, 1999). However, these models often do not consider how life course changes in SES (i.e., social mobility) or perceived relative status interact across levels of influence to predict health status, or how SES contributes to within-group variation in health.

\section{Operationalization of social mobility and social status}

As discussed earlier, most prior research on social mobility has used objective indicators of SES, namely occupational class data, to compute social mobility. Studies that use derived measures of objective social mobility tend to exclude those who may have exited the labor market and who do not report occupational class data (Harding, 2003). This method is problematic for studying social mobility among Latinos because Latinos with psychiatric disorders are more likely to exit the labor force (Chatterji, Alegría, Lu, \& Takeuchi, 2007). An alternative method involves the use of subjective social status (SSS) to measure perceptions of social mobility or relative social status differences (as examined in Nicklett \& Burgard, 2009).

SSS has been defined as an individual's perception of his or her standing in the socioeconomic hierarchy (Davis,1956). SSS is a well-validated multidimensional psychological construct theorized to capture nuanced aspects of past, current, and future social standing that may not be measured by objective SES (Adler, Epel, Castellazzo, \& Ickovics, 2000; Operario, Adler, \& Williams, 2004). SSS has strong and significant correlations with conventional measures of objective socioeconomic status. However, SSS is also a robust and independent predictor of physical health and mental health (e.g., depressive symptoms, self-rated health, respiratory illness, tobacco use), above and beyond objective indicators of SES such as household income, education, and occupation (Adler et al., 2000, 2008; Ostrove, Adler, Kuppermann, \& Washington, 2000; Reitzel et al., 2007; Singh-Manoux, Adler, \& Marmot, 2003). Moreover, SSS is independently associated with a decline in health over time in longitudinal studies (Singh-Manoux, Marmot, \& Adler, 2005). 
In regard to Latino health, SSS has been used in cross-sectional research with both Latino immigrants and non-immigrants. Research supports the incremental validity of SSS on health estimates beyond objective SES, and indicates that nativity and language use serve as correlates of SSS (Franzini \& Fernandez-Esquer, 2006; Reitzel et al., 2010), while others show SSS is less robust than income in predicting health status, especially among racial/ ethnic minorities and those who are socioeconomically disadvantaged (Macleod, Smith, Metcalfe, \& Hart, 2005; Ostrove et al., 2000).

To our knowledge, there is no empirical research on the relationship between objective indicators of social mobility and perceived social mobility or perceived changes in relative social status. Perceived social mobility might be associated with objective social mobility. More likely is that perceived social mobility, especially when measured using a psychological construct such as subjective social status, might serve as a proxy for psychological factors such as negative or positive affect (e.g., perception of self-efficacy, feelings of shame) and degree of physiological reactivity that are associated with relative social status as demonstrated in social comparison research (Fiske, 2010; Kraus, Piff, \& Keltner, 2009; Mendes, Blascovich, Major, \& Seery, 2001). Among immigrants, perceived differences in social status as a function of migration might reflect convergence or divergence of premigration expectations and post-migration lived realities.

\section{Social mobility, social status, and Latino immigrants}

One empirical article, to our knowledge, examined the association between changes in perceived social status and health among Latino immigrants. In particular, Nicklett and Burgard (2009) found a relationship between high degree of perceived downward social mobility and a major depressive episode among Latino and Asian immigrants. However, this article presented estimates for an aggregated sample of Latinos, and thus, did not account for variation across Latino subgroups. Yet, Latino subgroup differences in socioeconomic profiles are likely to shape perceived social mobility patterns and associations to health.

Latino sub-ethnic group variation in SES, migration flows, exit and reception contexts, extent of integration into the host country, experience of discrimination, pre-migration health, and ties to the country of origin are likely to influence opportunities for upward and downward social mobility (Alegría, Mulvaney-Day, et al., 2007; Guarnaccia et al., 2007; Jasso, Massey, Rosenzweig, \& Smith, 2004; Perez, Fortuna, \& Alegría, 2008; Portes, 2003). For example, Cubans report higher levels of education and household income relative to Mexicans, Puerto Ricans, and Other Latinos in the U.S. (U.S. Census Bureau, 2010), which might facilitate their potential for upward social mobility and evaluations of social status. Context of exit might also affect extent of integration into U.S. society, which might have implications for social mobility and perceived social status differences as function of migration circumstances. In particular, some evidence suggests that those who migrate to escape political violence engage in more rapid integration practices than those who migrate from countries at peace (Portes, 2003), which might have implications for the magnitude and direction of objectively and subjectively measured social mobility.

The same factors that might contribute to Latino sub-ethnic group variation in actual and perceived social mobility patterns might similarly play a role in accounting for Latino sub- 
ethnic group differences in the association between perceived social mobility and health. To that end, research suggests that for those who are socioeconomically deprived, incremental increases in SSS might be less significant for health than increases in material resources such as income, relative to those who are socioeconomically advantaged for whom concerns of relative status might be more relevant to health (Ostrove et al., 2000). Similarly, perceptions of downward or upward social mobility might be more important to health among those who have more socioeconomic resources. For example, as discussed above, Cubans report higher levels of educational attainment and income than other Latino subethnic groups (U.S. Census Bureau, 2010). Therefore, the association between perceptions of social mobility (that are derived from evaluations of SSS) might be more important for health among Cubans than among other Latino sub-ethnic groups such as Mexicans and Puerto Ricans who are more socioeconomically disadvantaged (Molina, Alegria, \& Mahalingam, 2012).

Alternatively, differences in the potential meaning and criteria used to evaluate perceptions of social status and social mobility might also differ by Latino sub-ethnic group and consequently, associations to health might also differ. For example, English language proficiency, U.S. nativity, and high perceptions of social trust and opportunities are associated with high evaluations of SSS among a Mexican sample (Franzini \& FernandezEsquer, 2006), and might be similarly associated with perceptions of upward social mobility. Puerto Ricans who are U.S. citizens by birth and exhibit higher English-proficiency levels than other Latino sub-ethnic groups (Guarnaccia et al., 2007) might use different criteria when assessing social status and might have greater expectations for social mobility than Mexicans because of their citizenship status. The greater expectations for social mobility among Puerto Ricans might increase their attention to social status and changes in social status relative to Mexicans. The heightened awareness to social status might subsequently contribute to stronger associations between perceptions of social mobility and health among Puerto Ricans in comparison to Mexicans.

Herein, we sought to explore perceptions of social status differences as a function of migration, or what we term post-migration perceived social mobility and Latino immigrant health. Our first objective was to explore Latino sub-ethnic group variation in the distribution of perceived social mobility. We expected to find significant subgroup variation in perceived social mobility profiles. Our second objective was to examine the association of perceived downward and upward social mobility with odds of a past-year major depressive episode (MDE) and of self-rated fair/poor physical health, and to explore whether subethnicity moderated these associations. We selected these two outcomes because of their established importance for public health. MDE is associated with high role impairment (Merikangas et al., 2007), while self-rated physical health is shown to predict mortality beyond provider assessments of health (Idler \& Benyamini, 1997). We hypothesized that perceived downward social mobility post-migration would be associated with increased odds of past-year MDE and self-rated fair/poor physical health relative to stable social status, whereas perceived upward social mobility would be associated with reduced odds of past-year MDE and of fair/poor physical health. Although the limited research in this area prevented us from rendering concrete hypotheses about sub-ethnic group differences in the relationship between perceptions of social mobility and health, we conjectured that 
perceptions of social mobility would have stronger associations to health among Puerto Ricans and Cubans. We were also interested in understanding the independent association between post-migration perceptions of social mobility and health after adjustment for previously shown sociodemographic and immigration correlates of Latino immigrant health (e.g., length of residence in the U.S.), pre-migration psychiatric history and physical health conditions, educational attainment, and household income.

\section{Methods}

\section{Data and sample}

Our data are drawn from the cross-sectional National Latino and Asian American Study (NLAAS), which was conducted between 2002 and 2003 and assessed racial/ethnic, socioeconomic, and contextual correlates of health and service use among Latino and Asian American adults using a multi-stage area probability sampling design (for more details see Alegria et al., 2004; Heeringa et al., 2004). The Institutional Review Boards of Cambridge Health Alliance, Harvard School of Medicine, University of Michigan, and University of Washington approved all study procedures. We restricted our analyses to the Latino immigrant subsample or those not born on the U.S. mainland $(N=1561)$. Our sample included Puerto Ricans born on the island of Puerto Rico $(n=206)$, and foreign-born Cubans $(n=489)$, Mexicans $(n=459)$, and Other Latinos $(n=407)$.

\section{Measures}

Perceived social mobility-We constructed a categorical measure of perceived upward social mobility, perceived downward social mobility, and perceived stable social status postmigration. Perceived social mobility was measured as the difference in perceived SSS if remained in the country of origin and current SSS in the U.S. (Nicklett \& Burgard, 2009). SSS was measured with the Mac-Arthur Scale of SSS (Adler et al., 2000; Ostrove et al., 2000). To evaluate current SSS in the U.S. respondents were instructed to "Think of this ladder as representing where people stand in the United States. What is the number to the right of the rung where you think you stand at this time in your life, relative to other people in the United States" based on job prestige, money, and education using a scale with values ranging from rung 10 (best off) to rung 1 (worst off) (Adler et al., 2000; Operario et al., 2004). Similarly, to evaluate perceived SSS if remained in the country of origin, respondents were instructed "Think of this ladder as representing where people stand in your country of origin. What is the number to the right of the rung where you think you would stand if you were still in your country of origin". As such, we used the difference between respondents' perceived social status if remained in the country of origin and current social status in U.S. to compute a measure of change in perceived social status, which we refer to herein as perceived social mobility. We constructed three perceived social mobility categories: any perceived downward social mobility (loss of 1-9 steps in SSS), stable (no change in SSS), and any perceived upward social mobility (gain of 1-9 steps in SSS). We conducted sensitivity analysis with seven (as per Nicklett \& Burgard, 2009) and five perceived social mobility categories and found that our results did not change substantially. Thus, we decided to use the more parsimonious model with three categories to increase statistical power to 
detect significant differences and limit the number of pair-wise comparisons given that our study drew from a smaller sample $(N=1561)$ than Nicklett and Burgard $(N=3056)$.

Physical health-Self-rated fair/poor physical health was assessed with a single question: "How would you rate your overall physical health— excellent, very good, good, fair, poor?" using a scale with corresponding values $1-5$. We generated a dichotomized variable that is equal to " 1 " if respondents endorsed fair or poor health and " 0 " if respondents selected any other category.

Major depressive episode-Past-year MDE was diagnosed using the World Mental Health- Composite International Diagnostic Interview (WMH-CIDI; Kessler \& Üstün, 2004). The WMH-CIDI is based on the criteria of the Diagnostic and Statistical Manual of Mental Disorders IV (DSM-IV) (American Psychiatric Association, 2000). The DSM-IV was the standard classification system of mental disorders used by mental health professionals in the United States at the time the data were collected (American Psychiatric Association, 2000). To meet criteria for past-year MDE, respondents had to endorse at least five of nine symptoms of depression during the same two week period, with at least one symptom including depressed mood or loss of interest/pleasure as described in the DSM-IV (American Psychiatric Association, 2000).

Socio-demographics—Respondents' age category at interview (18-34 [reference], 35$49,50-64,65$ or more), gender (male [reference] or female), duration in U.S. (under 5 years [reference] or over 5 years), English proficiency (good/excellent [reference]), and age at migration to the U.S. (0-6 [reference], 7-17, 18 and above) were included in our model as covariates. Sub-ethnicity was assessed as self-reported race/ancestry in Cuba, Mexico, Puerto Rico [reference], or Other Latin American country (e.g., Colombia, Guatemala, Dominican Republic). Objective SES was measured with household income (\$0-14,999 [reference], $\$ 15,000-34,999, \$ 35,000-74,999$, greater than or equal to $\$ 75,000)$ and educational level ( $\leq 1$ years [reference], 12 years, 13-15 years, $\geq 16$ years). Our coding of age, age at migration, and duration in the U.S. is consistent with prior research on immigrant health (Alegría, Sribney, et al., 2007). For example, we categorized age into four groups based on the distribution of the age variable in our sample; the four groups were similar in sample sizes, which facilitated comparisons by age group. Furthermore, we decided to use a dichotomous indicator for duration in the U.S. with five years as the cut-off because immigrants are eligible to participate in federal, local, or state entitlement/benefit programs after five years of residence in the U.S. Similarly, our age at migration categories correspond to important developmental stages to indicate whether an immigrant migrated during childhood (0-6), adolescence (7-17) or adulthood (18 and above).

Pre-migration physical health and psychiatric morbidity-We constructed two dichotomous variables to indicate premigration psychiatric history and pre-migration physical health. Respondents were coded as " 1 " for presence of pre-migration psychiatric disorder if they met $D S M-I V$ lifetime criteria for any of the following psychiatric conditions and we determined that the participant's reported age of onset occurred before his or her year of migration to the U.S. mainland. The psychiatric conditions included: major 
depressive episode, dysthymia, agoraphobia, panic disorder, social phobia, alcohol dependence, alcohol abuse, drug dependence, drug abuse, generalized anxiety disorder, posttraumatic stress disorder, bulimia, and anorexia. Similarly, respondents were coded as " 1 " for pre-migration physical health if they reported any of the following physical health conditions and an age of onset prior to migration. The physical health conditions included: arthritis or rheumatism, chronic back or neck problems, frequent or severe headaches, any other chronic pain, seasonal allergies, stroke, heart attack, heart disease, high blood pressure, asthma, tuberculosis, any other chronic lung disease like COPD or emphysema, diabetes or high blood sugar, ulcer, HIV infection or AIDS, epilepsy or seizures, and cancer.

\section{Analytic strategy}

All inferential procedures accounted for the complex survey design and were conducted using STATA statistical software version 10.1 (Stata Corporation, 2008). Survey weights were used for all estimation procedures. A small percentage of participants (approximately $4.2 \%$ ) had missing data for at least one of the covariates or outcome variables. We conducted sensitivity analyses using multiple imputation with the Imputation by Chained Equations (ICE) package in STATA. We imputed the dataset and combined the analytic results using the Multiple Imputation of Missing values. Parameter estimates using multiple imputation did not differ appreciably and thus we present our results for the non-imputed data. There was no evidence of multicollinearity.

Distribution of perceived social mobility and health outcomes-We used an Omnibus test to examine whether the distribution of perceived social mobility and mental and physical health outcomes differed by Latino sub-ethnicity. When the Omnibus test was significant, we conducted pair-wise comparisons to determine which subgroup differences were statistically significant. We made Bonferroni corrections to adjust for the multiple significance testing (Hardy, 1993). Puerto Rican migrants were selected as the reference group for all analyses because of the high rates of psychiatric disorders observed among this subgroup (Alegría, Mulvaney-Day, et al., 2007).

Perceived social mobility, MDE, and health-To determine age and gender adjusted prevalence rates of past-year MDE and self-rated fair/poor physical health across predictor variables we computed adjusted Wald tests. Next, we computed weighted logistic regression analyses with our full sample to test three models on the association between perceived social mobility and health. Model 1 examined the relationship between perceived social mobility and designated outcomes (i.e., MDE, fair/poor health) after initial adjustment for sub-ethnicity, perceived SSS in country of origin, age, gender, English proficiency, duration in U.S., and age at migration. Model 2 made an additional adjustment for either premigration psychiatric history or pre-migration physical health dependent on whether the outcome was MDE or self-rated physical health, respectively. Model 3 included final adjustments for objective SES (i.e., household income, educational attainment). Lastly, we examined whether sub-ethnicity moderated the association of perceived social mobility with our two health outcomes by formally testing for sub-ethnicity by perceived social mobility interactions in our final model. We first computed an Omnibus test to examine whether the interaction term was significant. When the Omnibus test was significant, we calculated 
derived odds of the interaction terms in our final multivariable model. We present the significant interactions in a separate table. When the interaction was significant, we calculated predictions that would enable us to plot our interactions and facilitate interpretation. We generated predictions using the "recycled predictions" method (Stata Corporation, 2008), which applies model coefficients to create predictions for each subethnic by perceived social mobility group, assuming that each subgroup has the average characteristics of the entire Latino immigrant population (for examples see Davern, Rodin, Blewett, \& Call, 2007; Graubard \& Korn, 1999).

\section{Results}

Table 1 presents the weighted descriptive characteristics of the NLAAS Latino immigrant sample and weighted age and gender adjusted prevalence rates for past-year MDE and selfrated fair/poor physical health stratified by sub-ethnicity. The distribution of age, English proficiency, income, and education differed substantially by subgroup. Puerto Ricans and Cubans were concentrated in the older age categories, whereas Cubans and Other Latinos were concentrated in the higher education categories. Over $80 \%$ of Cuban, Mexican, and Other Latino immigrants relative to $94.4 \%$ of Puerto Rican migrants lived in the U.S. mainland for over 5 years. Puerto Rican migrants were the largest subgroup to migrate as young children, whereas Mexicans, Cubans, and Other Latinos were more likely than Puerto Ricans to migrate as adults. Cubans, Mexicans, and Other Latinos were more represented in the lowest perceived SSS in the country of origin category (1-3) than Puerto Ricans. In contrast, Mexicans were less represented in the highest perceived SSS in the country of origin category (8-10) than Puerto Ricans.

Puerto Ricans had the highest weighted age and gender adjusted past-year prevalence rates for MDE (13.15\%) relative to Cubans (8.87\%) and Mexicans (7.04\%). Puerto Ricans (42.42\%) were significantly more likely than Cubans (22.07\%) and Other Latinos (25.94\%) to endorse fair/poor physical health after adjustment for age and gender. Cubans (34.85\%) and Other Latinos (26.26\%) were more likely than Puerto Ricans (17.89\%) to experience premigration physical health morbidity. Pre-migration rates of psychiatric disorder did not vary significantly by subgroup, although Mexicans were marginally $(p=0.06)$ less likely than Puerto Ricans to meet criteria for onset of a psychiatric disorder before migration to the U.S. mainland.

\section{Distribution of perceived social mobility}

Our first objective was to examine whether the distribution of perceived social mobility varied by Latino subgroup. Most Latino immigrants exhibited some degree of perceived social mobility with migration to the U.S. mainland, with a substantive minority experiencing no change in SSS (10.96-21.03\%). Consistent with our expectations, we found significant variation in the profiles of perceived social mobility across sub-ethnic groups. The overall distribution of perceived social mobility for Puerto Rican migrants significantly differed from that of Cuban $(p=0.000)$ and Mexican immigrants $(p=0.001)$. Over 53\% of Puerto Ricans, relative to $42.12 \%$ of Cubans and $41.67 \%$ of Mexicans perceived any downward social mobility. A significantly greater percentage of Cubans (46.92\%) and 
Mexicans (42.61\%) than Puerto Ricans (25.33\%) perceived any upward social mobility. Similarly, a greater percentage of Puerto Ricans (21.03\%) relative to Cubans (10.96\%) endorsed no change or stable SSS. We note that for both Mexican and Cuban immigrants the distribution of perceived social mobility was bimodal with over $80 \%$ distributed equally between the any perceived downward mobility and any perceived upward mobility categories.

\section{Perceived social mobility, MDE, and self-rated physical health}

Our second objective was to examine the independent association between perceived social mobility and mental health and physical health, and to test a Latino sub-ethnicity $\times$ perceived social mobility interaction. We report first the age and gender adjusted bivariate correlates of MDE prevalence rates and self-rated fair/poor physical health in the overall sample. We then report results from our adjusted regression models that account for sociodemographics, immigration-related variables, pre-migration psychiatric/physical health, objective SES, and interactions.

\section{Major depressive episode (MDE)}

Age and gender adjusted analyses (Table 2) show that neither downward nor upward perceived mobility, nor perceived SSS if remained in the country of origin were statistically associated with MDE. However, pre-migration psychiatric history was a significant bivariate correlate of MDE.

Adjusted regression models (Table 3 ) indicate that Latino immigrants who perceived any downward social mobility had higher odds of a past-year $\mathrm{MDE}(\mathrm{OR}=2.15 ; 95 \% \mathrm{CI}=1.04$, 4.47) relative to those with stable SSS after initial adjustment for perceived SSS if remained in country of origin, socio-demographic (age, gender, sub-ethnicity), and immigration variables (age at migration, English proficiency, duration in the U.S.) (Model 1). After accounting for pre-migration psychiatric history, any perceived downward social mobility relative to stable SSS resulted in higher odds of past year $\mathrm{MDE}(\mathrm{OR}=2.87 ; 95 \% \mathrm{CI}=1.05$, 7.86) (Model 2). Any perceived downward social mobility continued to be a significant correlate of past-year MDE $(\mathrm{OR}=2.88 ; 95 \% \mathrm{CI}=1.01,8.20)$ after adjustments for education and income (Model 3). Perceived upward social mobility relative to no change in social status was not associated with odds of MDE across our models when we did not take into account interaction effects.

The Omnibus test for the sub-ethnicity by perceived social mobility interaction for past-year MDE was statistically significant $(p=0.03)$. When the interaction terms were entered into the final multivariable model (Table 4), the association between any perceived downward social mobility and MDE was particularly pronounced for Puerto Rican migrants and Other Latino immigrants. Puerto Ricans and Other Latinos who perceived any downward social mobility had a two-fold to almost three-fold increase in odds of a past-year MDE relative to their sub-ethnic counterparts who experienced no change in SSS. In contrast, Cubans who perceived any upward social mobility had reduced odds in past-year MDE relative to their stable SSS Cuban counterparts who exhibited the second-highest rates of past-year MDE (Fig. 1). We note that Other Latinos who perceived any upward social mobility had 
increased odds of MDE relative to Other Latinos who did not perceive any change in SSS. In sum, Puerto Rican migrants who perceived downward social mobility had the highest prevalence rates of past-year MDE (13.89\%), followed by stable Cuban immigrants $(13.38 \%)$, and Other Latino immigrants who perceived upward mobility (10.29\%; Fig. 1).

\section{Self-rated fair/poor physical health}

Age and gender adjusted estimates of self-rated fair/poor physical health (see Table 2) followed similar trends as past-year MDE. Pre-migration physical health emerged as a significant correlate of self-rated fair/poor physical health. Perceived social mobility was not associated with self-rated fair/poor physical health. Latino immigrants in the lowest rungs of the social ladder in their countries of origin had they remained in the home country, with less than 11 years of education, with household incomes between $\$ 0$ and 14,999, and with limited English proficiency exhibited the highest prevalence rates for self-rated fair/poor physical health.

Our adjusted analyses (Table 5) suggest Latino immigrants who perceived any degree of downward social mobility $(\mathrm{OR}=2.04 ; 95 \% \mathrm{CI}=1.22,3.39)$ relative to stable SSS postmigration consistently had increased odds of self-rated fair/poor physical health (Model 1) after accounting for sub-ethnicity, age at migration, English proficiency, gender, age, duration in the U.S., and perceived SSS if remained in country of origin. The association between any perceived downward social mobility and self-rated fair/poor physical health remained significant after adjustment for pre-migration physical health history ( $\mathrm{OR}=1.95$; 95\% CI = 1.19, 3.21; Model 2), and household income and educational attainment (OR = $1.99 ; 95 \% \mathrm{CI}=1.21,3.27$; Model 3). The Omnibus test for the sub-ethnicity by perceived social mobility interaction on odds of fair/poor physical health was not statistically significant $(p=0.09)$.

It is possible that the statistically significant relationship observed between perceived social mobility or perceived social status differences as a function of migration, and health might be accounted for by an objective measure of social mobility. To address this concern, we conducted sensitivity analyses with a proxy measure of intergenerational objective social mobility to determine whether the association between perceived social mobility and odds of MDE and of self-rated fair/poor physical health was independent of the association between objective social mobility and health. Intergenerational objective social mobility was calculated as the difference between a respondent's years of education and his or her parent's highest education. We found that the direction and magnitude of the estimates did not change appreciably although there was a loss in statistical power. Perceived downward social mobility relative to no change in social status was marginally associated with increased odds of MDE in models adjusting for intergenerational objective social mobility $(\mathrm{OR}=2.57 ; 95 \% \mathrm{CI}=0.91,7.22)$. In addition, Latino immigrants who perceived downward social mobility relative to no change in social status had significantly higher odds of selfrated fair/poor physical health in models adjusting for intergenerational objective social mobility ( $\mathrm{OR}=2.06 ; 95 \% \mathrm{CI}=1.10,3.85)$. We also note that when an adjustment for intergenerational objective social mobility was added to the MDE model with interaction 
terms, the Latino sub- ethnicity and perceived social mobility interactions became marginal but were in the same direction and of similar magnitude as documented in Table 4.

\section{Discussion}

Our results provide a first look into the distribution of perceived social mobility, or perceived social status differences as a function of migration, among Latino immigrants from different sub-ethnic groups. Cuban and Mexican immigrants were more likely than Puerto Rican migrants to perceive any upward social mobility post-migration, while Puerto Rican migrants relative to Cuban and Mexican (but not Other Latino) immigrants were more likely to perceive any downward social mobility. These differences in perceived social mobility patterns extend and converge with prior research documenting post-migration income and education differentials between Cubans, Mexicans, and Puerto Ricans, with Cubans holding higher levels of education and household income relative to the other subgroups (U.S. Census Bureau, 2010).We note that among Cubans and Mexicans, perceived social mobility exhibited a bimodal distribution, which might reflect differences in the socioeconomic status profiles of Cuban and Mexican immigrants as a function of when immigrants arrived to the U.S. For example, research shows that Cuban immigrants who arrived after the 1980s experienced less receptive contexts in the U.S. mainland than cohorts arriving before the 1980s, which might contribute to perceptions of downward social mobility among the post-1980s cohort of Cuban immigrants (Cislo, Spence, \& Gayman, 2010). To this end, in our sample, Cuban immigrants who arrived after 1980s composed the majority of Cubans in the perceived downward social mobility category ( $n=117$ out of 202).

Consistent with prior research on the adverse association between relative low subjective social status and health (Kondo, Kawachi, Subramanian, Takeda, \& Yamagata, 2008; Nicklett \& Burgard, 2009; Pham-Kanter, 2009; Wilkinson \& Pickett, 2007), any perceived downward social mobility was associated with higher odds of self-rated fair/poor physical health and past-year MDE. In other words, Latino immigrants who reported a social status in the U.S. mainland that was lower than their perceived social status in their country of origin had they remained in the home country, exhibited higher odds of past-year MDE and selfrated fair/poor physical health, compared to those who perceived no differences in social status as a function of migration. Our patterns of association converge with those of Nicklett and Burgard (2009) who also used a subjective measure of social mobility to examine associations to MDE and found an adverse association between perceived downward social mobility and MDE. Furthermore, the odds ratios for MDE and fair/poor health did not change appreciably after we adjusted for a proxy measure of intergenerational objective social mobility in sensitivity analyses. Thus, perceptions of downward social mobility or perceived losses in social status as a function of migration are important correlates of Latino immigrant health, that are likely independent of objective measures of relative status.

Although the cross-sectional data used in this analysis prevent us from making causal inferences, prior research suggests that perceived low social status may impart a deleterious effect on mental and physical health through the activation of psychological and physiological stress pathways that engender anxiety, negative affect, and a sense of 
perceived threat and loss of personal control (Gallo \& Matthews, 2003; McEwen, 1998; Wilkinson, 1999). The social comparison literature also lends support to the stipulation that negative affect and physiological reactivity may be potential mechanisms mediating the relationship between low social status and poor health. For example, individuals who adopt a position of low social status in experimental tasks exhibit cardiovascular patterns of reactivity and negative affect that are associated with a state of perceived threat, shame, and low sense of personal control (Fiske, 2010; Kraus et al., 2009; Mendes et al., 2001). Among Latino immigrants, inconsistencies in pre-migration and post-migration social statuses, lifestyles, and expectations, such as underemployment post-migration despite high educational attainment in the country of origin (House \& Harkins, 1975) might activate these emotional and physiological distress reactions. Chronic activation of these physiological and psychological pathways, in the context of divergent pre-migration and post-migration expectations and experiences, might subsequently contribute to Latino subgroup variation in immigrant health. We note that in our sample perceptions of downward social mobility were not associated with duration in the U.S. mainland. This suggests that perceptions of loss of relative social status might be independent from U.S. tenure and might be based on early immigrant experiences integrating into the host country. Therefore, perceived downward social mobility when measured with a psychological construct such as subjective social status might be a proxy for negative affect and physiological reactivity that are associated with enduring perceptions of relative low social status.

We also found that Latino sub-ethnicity moderated the relationship between perceived social mobility and past-year MDE, but not fair/poor health. The association between any perceived downward social mobility and past-year MDE was particularly pronounced for Puerto Ricans and Other Latinos, which partly supported our hypothesis. In other words, Puerto Rican and Other Latino immigrants who perceived they held a lower social status in the U.S. relative to their perceived social status in their country of origin had they remained in the sending country, exhibited higher odds of MDE relative to those who did not perceive any differences in social status related to migration. This finding might reflect greater divergence in pre-migration expectations and post-migration lived experiences, increased attention to evaluations of and changes in social status, and psychological stress reactions associated with a marginalized social position, which jointly might heighten vulnerability to MDE. For example, Puerto Ricans might have greater expectations for post-migration upward social mobility due to their status as U.S. citizens and might subsequently experience heightened awareness of changes in social status and greater risks for psychopathology in the context of unmet expectations for upward social mobility (Murphy \& Mahalingam, 2006).

Our results also suggest that perceived upward social mobility has differential associations to physical health and mental health, which converges with the previous literature on objective and subjective social mobility and health (Colen et al., 2006; Heraclides \& Brunner, 2010; Nicklett \& Burgard, 2009). Perceived upward social mobility was not associated with ratings of self-rated fair/poor physical health. The lack of an observed relationship between upward social mobility and self-rated fair/poor health might reflect how low socioeconomic exposures early in life or an accumulation of risks in childhood 
might outweigh the psychosocial benefits of perceived upward social mobility in adulthood (Stansfeld, Clark, Rodgers, Caldwell, \& Power, 2010). Future research should examine how different perceived socioeconomic trajectories, including stable low, stable high, upward mobility, and downward mobility, are associated with health among Latino immigrants. On account of the small sample size in our analysis, we were unable to draw conclusions from an analysis of the association between four perceived social mobility categories (including a disaggregated stable group) and health because the confidence intervals were too large to make precise inferences about the population. Another explanation for the non-significant findings between upward social mobility and fair/poor health is that Latino immigrants might reside in areas with high residential racial segregation and high concentrations of poverty regardless of SSS, which might offset the potential physical health gains incurred by perceived upward social mobility (Williams, Mohammed, Leavell, \& Collins, 2010).

In accord with our expectations, perceived changes in social status after migration were particularly important to estimates of MDE for Cuban immigrants. In particular, perceived upward social mobility was associated with reduced odds of past-year MDE for Cuban immigrants. Changes in social status might be particularly important to the mental health of Cubans because of their socioeconomically advantaged positions relative to other Latino subethnic groups who might have fewer socioeconomic resources and for whom increases in material resources might have a stronger association to health than perceptions of social status (Ostrove et al., 2000).We note that Cuban immigrants who perceived stable SSS exhibited the second-highest prevalence rates for past-year MDE across Latino sub-ethnic groups. It is possible that this finding is capturing differences in psychosocial exposures by cohort of arrival among Cubans. In our sample, Cuban immigrants who arrived in the U.S. after the 1980s composed $61.81 \%$ of Cubans in the stable SSS category $(n=34)$. Prior research indicates that the post-1980s cohort of Cuban immigrants was more likely to occupy positions of low SES, encounter hostile reception contexts, and have limited familial and social supports relative to earlier cohorts of Cuban immigrants (Cislo et al., 2010; Rumbaut, 2006). Thus, the effects associated with an accumulation of adverse pre-migration and post-migration psychosocial exposures and limited social resources might together increase risk for psychopathology. However, it is also possible that this finding is driven by the small sample size in this cell $(n=55)$. Future research should examine how estimates of mental health among immigrant groups change as a function of year of arrival (for an example see Hamilton \& Hummer, 2011).

In contrast, perceived upward social mobility was associated with increased odds of MDE for Other Latino immigrants. Thus, Other Latino immigrants who perceived their social status in the U.S. mainland as higher than their perceived social status in their home country had they stayed in their country of origin, had significantly higher odds of MDE compared to those who did not perceive any social status differences with migration. Among Other Latinos, upward social mobility might be associated with increased social and familial pressures to send economic remittances to relatives and kin left behind in the country of origin who often depend on remittances to sustain local household economies. The pressure associated with expectations to send economic remittances might be particularly acute for immigrants from Other Latin American countries such as the Dominican Republic where 
remittances comprise a substantive percentage of the GDP (World Bank, 2011). Perceptions of upward social mobility might also be associated with exposure to discrimination and intergenerational family conflict, both of which are potential pathways to increased risk of past-year psychiatric disorder for Latino immigrants over time (Cook et al., 2009). Our findings underscore the need for mixed methods research to better understand Latino subethnic group differences in the expectations, criteria, and experiences of social mobility, social status, and associations to mental health.

\section{Limitations}

Although our paper makes significant contributions to the literature on Latino immigrant health, there are certain limitations that warrant discussion. First, the data collected within the NLAAS are cross-sectional and thus do not allow us to assess causation. It is possible that past-year major depressive episode and self-rated fair/poor physical health may result in perceived downward social mobility, rather than the inverse. Although we cannot make causal inferences, a significant strength of this study is that we adjusted for pre-migration physical health and psychiatric morbidity to limit confounding due to health selection. Our results indicate that between 11 and 35\% of Latino immigrants experience a psychiatric disorder or physical health condition with an age of onset before migration to the U.S. mainland, which calls into question the "healthy migrant" hypothesis that stipulates that the lower mortality and better health profiles of immigrants is due to the migration of the relatively healthier segments of the population (Jasso et al., 2004). Second, self-rated fair/ poor physical health was assessed in English or Spanish. Recent research suggests estimates of fair/poor health among Spanish-speaking Latinos might be biased due to the translation of fair into "regular" in Spanish, which has a more positive connotation and might result in over-endorsement of the fair/poor health category (Viruell-Fuentes, Morenoff, Williams, \& House, 2010). We conducted a sensitivity analysis adjusting for language of interview and found that our estimates did not change appreciably, thus language of interview is likely not confounding our estimates. Third, our measure of perceived social mobility does not take into account different absolute positions on the SSS ladder. Future studies with larger samples should examine the extent to which degree of change in social status is related to health.

Fourth, we operationalized perceived social mobility as the difference between participants' SSS in the country of origin had they remained in their home country and participants' current SSS in the U.S. mainland. As such, our measure of SSS in the country of origin is based on a hypothetical experience or a perception of a counterfactual, and thus might raise concerns regarding the measurement of perceived social mobility. However, despite the wording of the survey question, we found that the relationship between perceived SSS in the country of origin was positively associated with parental education $(r=0.20, p<0.001)$. Although we did not have an actual measure of pre-migration social status other than parental education, it is possible that the measure of perceived SSS in the country of origin in actuality is drawing upon respondents' evaluations of their childhood socioeconomic circumstances and thus might serve as a crude proxy for pre-migration social status. Future studies on immigrant health should carefully measure and incorporate indicators of pre- 
migration social context such as individual-level social status and socioeconomic status to investigate the relationship between objective and subjective social mobility and health.

\section{Conclusion}

Latino immigrants exhibit substantial sub-ethnic group variation in the distribution of perceived social status differences as a function of migration, or what we term perceived social mobility, and its associations to health. Perceived downward social mobility postmigration to the U.S. mainland might be an important correlate of physical and mental health among Latino immigrants that is independent of objective social mobility. Latino subethnic group differences in awareness of perceived changes in social status or perceived social mobility might help account for within-group variation in Latino mental health. The association between perceived downward social mobility or loss of social status and pastyear MDE was particularly pronounced for Puerto Ricans. Yet, both perceived upward and downward social mobility were associated with increased odds of past-year MDE only for Other Latino immigrants, whereas perceived upward social mobility was associated with reduced odds of MDE for Cuban immigrants. Increased attention should be devoted toward understanding whether determinants and experiences of social status and social mobility differ by Latino sub-ethnic group, especially among recent cohorts of immigrants. Future research should use prospective designs to examine the causal relationship between perceived social mobility and health, and the physiological and psychological pathways linking perceived socioeconomic trajectories and mental and physical health.

\section{Acknowledgments}

C. Alcántara was supported by the W.K. Kellogg Foundation while at Harvard School of Public Health and by K24 HL-84034 and HL115941-01S1 from the National Heart, Lung, and Blood Institute while at Columbia University Medical Center. M. Alegría and C. Chen were provided research support from the National Center on Minority Health and Health Disparities (UPR-CHA Research Center of Excellence: Making a Difference for Latino Health: \#5 P60MD002261). The authors would like to thank Kristine Molina, Tod Hamilton, and Patrick Shrout, as well as the Susan J. Elliot (Senior Editor) and anonymous reviewers for their helpful comments and suggestions. The content of this manuscript is solely the responsibility of the authors and does not necessarily represent the official views of the W.K. Kellogg Foundation or the National Institutes of Health.

\section{References}

Abraido-Lanza AF, Dohrenwend BP, Ng-Mak DS, Turner JB. The Latino mortality paradox: a test of the "salmon bias" and healthy migrant hypotheses. American Journal of Public Health. 1999; 89:1543-1548. [PubMed: 10511837]

Adler NE, Epel ES, Castellazzo G, Ickovics JR. Relationship of subjective and objective social status with psychological and physiological functioning: preliminary data in healthy, white women. Health Psychology. 2000; 19:586-592. [PubMed: 11129362]

Adler NE, Singh-Manoux A, Schwartz J, Stewart J, Matthews K, Marmot MG. Social status and health: a comparison of British civil servants in Whitehall-II with European- and AfricanAmericans in CARDIA. Social Science \& Medicine. 2008; 66:1034-1045. [PubMed: 18180089]

Alegria M. The challenge of acculturation measures: what are we missing? A commentary on Thomson \& Hoffman-Goetz. Social Science \& Medicine. 2009; 69:996-998. [PubMed: 19664868]

Alegría M, Canino G, Shrout PE, Woo M, Duan N, Vila D, et al. Prevalence of mental illness in immigrant and non-immigrant U.S. Latino groups. The American Journal of Psychiatry. 2008; 165:359-369. [PubMed: 18245178] 
Alegría M, Mulvaney-Day N, Torres M, Polo A, Cao Z, Canino G. Prevalence of psychiatric disorders across Latino subgroups in the United States. American Journal of Public Health. 2007; 97:68-75. [PubMed: 17138910]

Alegría M, Sribney W, Woo M, Torres M, Guarnaccia P. Looking beyond nativity: the relation of age of immigration, length of residence, and birth cohorts to the risk of onset of psychiatric disorders for Latinos. Research in Human Development. 2007; 4:19-47. [PubMed: 19412354]

Alegria M, Takeuchi D, Canino G, Duan N, Shrout P, Meng X-L. Considering context, place and culture: the National Latino and Asian American study. International Journal of Methods in Psychiatric Research. 2004; 13:208-220. [PubMed: 15719529]

American Psychiatric Association. Diagnostic and statistical manual of mental disorders: DSM-IV-TR. Washington, DC: American Psychiatric Association; 2000.

American Psychological Association, Presidential Task Force on Immigration. Crossroads: The psychology of immigration in the new century. 2012. Retrieved from http://www.apa.org/topics/ immigration/report.aspx

Bates LM, Acevedo-Garcia D, Alegría M, Krieger N. Immigration and generational trends in body mass index and obesity in the United States: results of the National Latino and Asian American survey 2002-2003. American Journal of Public Health. 2008; 98:70-77. [PubMed: 18048787]

Broman CL. Social mobility and hypertension among blacks. Journal of Behavioral Medicine. 1989; 12:123-134. [PubMed: 2788221]

Chatterji P, Alegría M, Lu M, Takeuchi D. Psychiatric disorders and labor market outcomes: evidence from the National Latino and Asian American study. Health Economics. 2007; 16:1069-1090. [PubMed: 17294497]

Chen J, Gee GC, Spencer MS, Danziger SH, Takeuchi DT. Perceived social standing among Asian immigrants in the US: do reasons for immigration matter? Social Science Research. 2009; 38:858869. [PubMed: 20160989]

Chittleborough CR, Taylor AW, Baum FE, Hiller JE. Monitoring inequities in self-rated health over the life course in population surveillance systems. American Journal of Public Health. 2009; 99:680-689. [PubMed: 19197081]

Cislo AM, Spence NJ, Gayman MD. The mental health and psychosocial adjustment of Cuban immigrants in south Florida. Social Science \& Medicine. 2010; 71:1173-1181. [PubMed: 20643498]

Cleland VJ, Ball K, Magnussen C, Dwyer T, Venn A. Socioeconomic position and the tracking of physical activity and cardiorespiratory fitness from childhood to adulthood. American Journal of Epidemiology. 2009; 170:1069-1077. [PubMed: 19767351]

Colen CG, Geronimus AT, Bound J, James SA. Maternal upward socioeconomic mobility and blackewhite disparities in infant birthweight. American Journal of Public Health. 2006; 96:2032-2039. [PubMed: 17018818]

Cook B, Alegría M, Lin JY, Guo J. Pathways and correlates connecting Latinos' mental health with exposure to the United States. American Journal of Public Health. 2009; 99:2247-2254. [PubMed: 19834004]

Das-Munshi J, Leavey G, Stansfeld SA, Prince MJ. Migration, social mobility and common mental disorders: critical review of the literature and meta-analysis. Ethnicity \& Health. 2011; 17:17-53. [PubMed: 22074468]

Davern M, Rodin H, Blewett LA, Call KT. Are the current population survey uninsurance estimates too high? An examination of the imputation process. Health Services Research. 2007; 42:20382055. [PubMed: 17850532]

Davis JA. Status symbols and the measurement of status perception. Sociometry. 1956; 19:154-165.

Deaux K. Surveying the landscape of immigration: social psychological perspectives. Journal of Community \& Applied Social Psychology. 2000; 10:421-431.

Fiske ST. Envy up, scorn down: how comparison divides us. American Psychologist. 2010; 65:698706. [PubMed: 21058760]

Franzini L, Fernandez-Esquer ME. The association of subjective social status and health in lowincome Mexican-origin individuals in Texas. Social Science \& Medicine. 2006; 63:788-804. [PubMed: 16580107] 
Gallo LC, Bogart LM, Vranceanu A-M, Matthews KA. Socioeconomic status, resources, psychological experiences, and emotional responses: a test of the reserve capacity model. Journal of Personality and Social Psychology. 2005; 88:386-399. [PubMed: 15841865]

Gallo LC, Matthews KA. Understanding the association between socioeconomic status and physical health: do negative emotions play a role? Psychological Bulletin. 2003; 129:10-51. [PubMed: 12555793]

Geronimus AT. The weathering hypothesis and the health of African-American women and infants: evidence and speculations. Ethnicity \& Disease. 1992; 2:207-221. [PubMed: 1467758]

Graubard B, Korn E. Predictive margins with survey data. Biometrics. 1999; 55:652. [PubMed: 11318229]

Guarnaccia PJ, Pincay IM, Alegría M, Shrout PE, Lewis-Fernández R, Canino GJ. Assessing diversity among Latinos: results from the NLAAS. Hispanic Journal of Behavioral Sciences. 2007; 29:510 534. [PubMed: 19672330]

Hallqvist J, Lynch J, Bartley M, Lang T, Blane D. Can we disentangle life course processes of accumulation, critical period and social mobility? An analysis of disadvantaged socio-economic positions and myocardial infarction in the Stockholm heart epidemiology program. Social Science\&Medicine. 2004; 58:1555-1562. [PubMed: 14759698]

Hamilton TG, Hummer RA. Immigration and the health of U.S. black adults: does country of origin matter? Social Science \& Medicine. 2011; 73:1551-1560. [PubMed: 21982630]

Harding S. Social mobility and self-reported limiting long-term illness among West Indian and South Asian migrants living in England and Wales. Social Science \& Medicine. 2003; 56:355-361. [PubMed: 12473320]

Hardy, MA. Regression with dummy variables. Thousand Oaks, CA: Sage Publications, Inc; 1993.

Hart CL, Smith GD, Blane D. Social mobility and 21 year mortality in a cohort of Scottish men. Social Science \& Medicine. 1998; 47:1121-1130. [PubMed: 9723857]

Heeringa SG, Wagner J, Torres M, Duan N, Adams T, Berglund P. Sample designs and sampling methods for the collaborative psychiatric epidemiology studies (CPES). International Journal of Methods in Psychiatric Research. 2004; 13:221-240. [PubMed: 15719530]

Heller RF, McElduff P, Edwards R. Impact of upward social mobility on population mortality: analysis with routine data. BMJ. 2002; 325:134. [PubMed: 12130608]

Heraclides A, Brunner E. Social mobility and social accumulation across the life course in relation to adult overweight and obesity: the Whitehall II study. Journal of Epidemiology \& Community Health. 2010; 64:714-719. [PubMed: 19737739]

House JS, Harkins EB. Why and when is status inconsistency stressful? American Journal of Sociology. 1975; 81:395-412.

Idler EL, Benyamini Y. Self-rated health and mortality: a review of twenty-seven community studies. Journal of Health \& Social Behavior. 1997; 38:21-37. [PubMed: 9097506]

Jasso, G.; Massey, DS.; Rosenzweig, MR.; Smith, JP. Immigrant health: selectivity and acculturation. In: Anderson, NB.; Bulatao, RA.; Cohen, B., editors. Critical perspectives on racial and ethnic differences in health in late life. Washington DC: The National Academies Press; 2004. p. 227-266.

Kessler RC, Üstün TB. The world mental health (WMH) survey initiative version of the World Health Organization (WHO) composite international diagnostic interview (CIDI). International Journal of Methods in Psychiatric Research. 2004; 13:93-121. [PubMed: 15297906]

Kondo N, Kawachi I, Subramanian SV, Takeda Y, Yamagata Z. Do social comparisons explain the association between income inequality and health?: relative deprivation and perceived health among male and female Japanese individuals. Social Science \& Medicine. 2008; 67:982-987. [PubMed: 18632196]

Kraus MW, Piff PK, Keltner D. Social class, sense of control, and social explanation. Journal of Personality and Social Psychology. 2009; 97:992-1004. [PubMed: 19968415]

Loucks EB, Pilote L, Lynch JW, Richard H, Almeida ND, Benjamin EJ, et al. Life course socioeconomic position is associated with inflammatory markers: the Framingham Offspring study. Social Science \& Medicine. 2010; 71:187-195. [PubMed: 20430502] 
Macleod J, Smith GD, Metcalfe C, Hart C. Is subjective social status a more important determinant of health than objective social status? Evidence from a prospective observational study of Scottish men. Social Science \& Medicine. 2005; 61:1916-1929. [PubMed: 15916842]

Mahalingam, R. Cultural psychology of immigrants: an introduction. In: Mahalingam, R., editor. Cultural psychology of immigrants. Mahwah, NJ: Lawrence Erlbaum Associates Publishers; 2006. p. 1-14.

McEwen BS. Seminars in medicine of the Beth Israel Deaconess Medical Center: protective and damaging effects of stress mediators. The New England Journal of Medicine. 1998; 338:171-179. [PubMed: 9428819]

Mendes WB, Blascovich J, Major B, Seery M. Challenge and threat responses during downward and upward social comparisons. European Journal of Social Psychology. 2001; 31:477-497.

Merikangas KR, Ames M, Cui L, Stang PE, Ustun TB, Von Korff M, et al. The impact of comorbidity of mental and physical conditions on role disability in the US adult household population. Archives of General Psychiatry. 2007; 64:1180-1188. [PubMed: 17909130]

Molina KM, Alegria M, Mahalingam R. A multiple-group path analysis of the role of everyday discrimination on self-rated physical health among Latina/os in the USA. Annals of Behavioral Medicine. 2012; 2013(45):33-44.

Müller, W. Mobility: social. In: Neil, JS.; Paul, BB., editors. International encyclopedia of the social \& behavioral sciences. Oxford: Pergamon; 2001. p. 9918-9924.

Murphy EJ, Mahalingam R. Perceived congruence between expectations and outcomes: implications for mental health among Caribbean immigrants. American Journal of Orthopsychiatry. 2006; 76:120-127. [PubMed: 16569136]

Myers HF. Ethnicity- and socio-economic status-related stresses in context: an integrative review and conceptual model. Journal of Behavioral Medicine. 2009; 32:9-19. [PubMed: 18989769]

Nicklett EJ, Burgard SA. Downward social mobility and major depressive episodes among Latino and Asian-American immigrants to the United States. American Journal of Epidemiology. 2009; 170:793-801. [PubMed: 19671834]

Nilsson PM, Nilsson JA, Ostergren PO, Berglund G. Social mobility, marital status, and mortality risk in an adult life course perspective: the Malmo preventive project. Scandinavian Journal of Public Health. 2005; 33:412-423. [PubMed: 16332606]

Operario D, Adler NE, \&Williams DR. Subjective social status: reliability and predictive utility for global health. Psychology \& Health. 2004; 19:237-246.

Ostrove JM, Adler NE, Kuppermann M, Washington AE. Objective and subjective assessments of socioeconomic status and their relationship to self-rated health in an ethnically diverse sample of pregnant women. Health Psychology. 2000; 19:613-618. [PubMed: 11129365]

Otero-Rodriguez A, Leon-Munoz LM, Banegas JR, Guallar-Castillon P, Rodriguez-Artalejo F, Regidor E. Life-course socioeconomic position and change in quality of life among older adults: evidence for the role of a critical period, accumulation of exposure and social mobility. Journal of Epidemiology \& Community Health. 2010; 65:964-971. [PubMed: 20974837]

Palloni A, Arias E. Paradox lost: explaining the Hispanic adult mortality advantage. Demography. 2004; 41:385-415. [PubMed: 15461007]

Perez DJ, Fortuna L, Alegría M. Prevalence and correlates of everyday discrimination among U.S. Latinos. Journal of Community Psychology. 2008; 36:421-433. [PubMed: 19960098]

Pham-Kanter G. Social comparisons and health: can having richer friends and neighbors make you sick? Social Science \& Medicine. 2009; 69:335-344. [PubMed: 19515477]

Pollitt RA, Rose KM, Kaufman JS. Evaluating the evidence for models of life course socioeconomic factors and cardiovascular outcomes: a systematic review. BMC Public Health. 2005; 5:7. [PubMed: 15661071]

Portes A. Conclusion: theoretical convergencies and empirical evidence in the study of immigrant transnationalism. International Migration Review. 2003; 37:874-892.

Portes, A.; Rumbaut, RG. Immigrant America: A portrait. Berkeley, CA: University of California Press; 2006.

Portes A, Zhou M. The new second generation: segmented assimilation and its variants. The Annals of the American Academy of Political and Social Science. 1993; 530:74-96. 
Reitzel LR, Mazas CA, Cofta-Woerpel L, Vidrine JI, Businelle MS, Kendzor DE, et al. Acculturative and neighborhood influences on subjective social status among Spanish-speaking Latino immigrant smokers. Social Science \& Medicine. 2010; 70:677-683. [PubMed: 20044186]

Reitzel LR, Vidrine JI, Li Y, Mullen PD, Velasquez MM, Cinciripini PM, et al. The influence of subjective social status on vulnerability to postpartum smoking among young pregnant women. American Journal of Public Health. 2007; 97:1476-1482. [PubMed: 17600249]

Rosvall M, Chaix B, Lynch J, Lindstrom M, Merlo J. Similar support for three different life course socioeconomic models on predicting premature cardiovascular mortality and all-cause mortality. BMC Public Health. 2006; 6:203. [PubMed: 16889658]

Rumbaut, RG. The making of a people. In: Tienda, M.; Mitchell, F., editors. Hispanics and the future of America. Washington DC: The National Academies Press; 2006. p. 16-65.

Singh-Manoux A, Adler NE, Marmot MG. Subjective social status: its determinants and its association with measures of ill-health in the Whitehall II study. Social Science \& Medicine. 2003; 56:13211333. [PubMed: 12600368]

Singh-Manoux A, Marmot MG, Adler NE. Does subjective social status predict health and change in health status better than objective status? Psychosomatic Medicine. 2005; 67:855-861. [PubMed: 16314589]

Smith BT, Lynch JW, Fox CS, Harper S, Abrahamowicz M, Almeida ND, et al. Life-course socioeconomic position and type 2 diabetes mellitus: the Framingham Offspring study. American Journal of Epidemiology. 2011; 173:438-447. [PubMed: 21242301]

Sorlie PD, Backlund E, Johnson NJ, Rogot E. Mortality by Hispanic status in the United States. JAMA: The Journal of the American Medical Association. 1993

Stansfeld SA, Clark C, Rodgers B, Caldwell T, Power C. Repeated exposure to socioeconomic disadvantage and health selection as life course pathways to mid-life depressive and anxiety disorders. Social Psychiatry \& Psychiatric Epidemiology. 2010

Stark O, Bloom DE. The new economics of labor migration. The American Economic Review. 1985; 75:173-178.

Stata Corporation. Stata statistical software release 10.1. College Station, Texas: Stata Corporation; 2008.

Tiffin PA, Pearce MS, Parker L. Social mobility over the life course and self reported mental health at age 50: prospective cohort study. Journal of Epidemiology \& Community Health. 2005; 59:870872. [PubMed: 16166361]

Timms DW. Social mobility and mental health in a Swedish cohort. Social Psychiatry \& Psychiatric Epidemiology. 1996; 31:38-48. [PubMed: 8821922]

Timms DW. Gender, social mobility and psychiatric diagnoses. Social Science \& Medicine. 1998; 46:1235-1247. [PubMed: 9572613]

United States Census Bureau. Current population survey, annual social and economic supplement. 2010. United States Census Bureau. Retrieved from http://www.census.gov/did/www/saipe/data/ model/info/cpsasec.html

Vega WA, Kolody B, Aguilar-Gaxiola S, Alderete E, Catalano R, Caraveo-Anduaga J. Lifetime prevalence of DSM-III-R psychiatric disorders among urban and rural Mexican Americans in California. Archives of General Psychiatry. 1998; 55:771-778. [PubMed: 9736002]

Viruell-Fuentes EA, Morenoff JD, Williams DR, House JS. Language of interview, self-rated health, and the other Latino health puzzle. American Journal of Public Health. 2010; 2009:175455.

Watt HC, Carson C, Lawlor DA, Patel R, Ebrahim S. Influence of life course socioeconomic position on older women's health behaviors: findings from the British women's heart and health study. American Journal of Public Health. 2009; 99:320-327. [PubMed: 19059863]

Wilkinson, RG. Health, hierarchy, and social anxiety. In: Adler, NE.; Marmot, M.; McEwen, BS.; Stewart, J., editors. Socioeconomic status and health in industrial nations: Social, psychological, and biological pathways. New York, NY: New York Academy of Sciences; 1999. p. 48-63.

Wilkinson RG, Pickett KE. The problems of relative deprivation: why some societies do better than others. Social Science \& Medicine. 2007; 65:1965-1978. [PubMed: 17618718] 
Williams DR, Mohammed SA, Leavell J, Collins C. Race, socioeconomic status, and health: complexities, ongoing challenges, and research opportunities. Annals of the New York Academy of Sciences. 2010; 1186:69-101. [PubMed: 20201869]

World Bank. Migration and remittances fact book, 2011. Washington, DC: World Bank; 2011.

Zhou M. Segmented assimilation: issues, controversies, and recent research on the new second generation. International Migration Review. 1997; 31:975-1008. [PubMed: 12293212] 


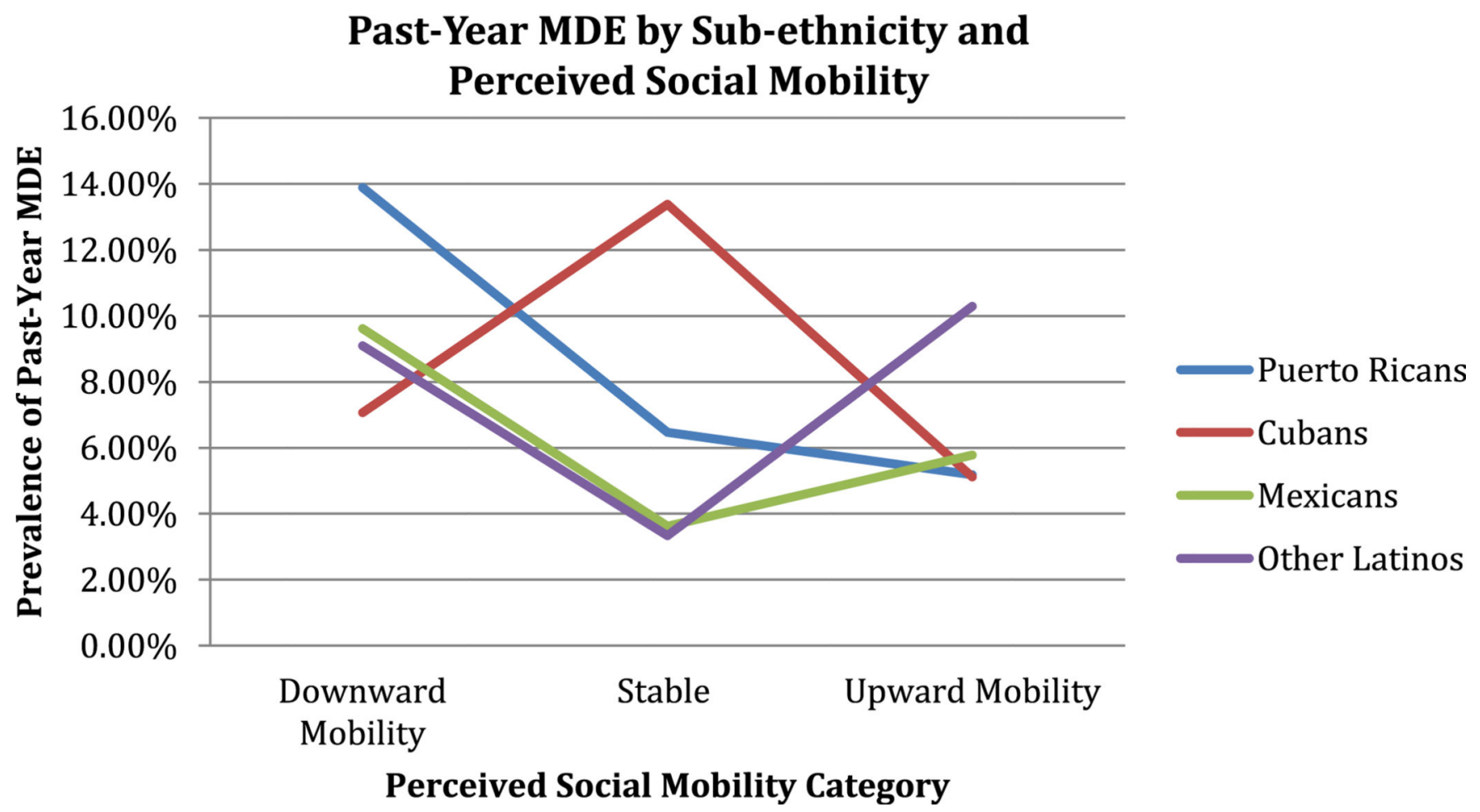

Fig 1.

Prevalence estimates of past-year major depressive episode (MDE) based on recycled predictions method. 


\section{Table 1}

Weighted descriptive characteristics and age and gender adjusted prevalence rates of past-year MDE and fair/ poor health by sub-ethnicity, NLAAS (2002-2003) $N=1561$.

\begin{tabular}{|c|c|c|c|c|c|c|c|c|c|}
\hline \multirow{3}{*}{ Sample size $(n)$} & \multirow{2}{*}{\multicolumn{2}{|c|}{$\frac{\text { Puerto Ricans }}{206}$}} & \multicolumn{2}{|c|}{ Cubans } & \multicolumn{2}{|c|}{ Mexicans } & \multicolumn{2}{|c|}{ Other Latinos } & \multirow{3}{*}{$\begin{array}{l}\text { Omnibus tests } \\
\text { p Value }\end{array}$} \\
\hline & & & \multicolumn{2}{|l|}{489} & \multicolumn{2}{|l|}{459} & \multicolumn{2}{|l|}{407} & \\
\hline & Mean & SE & Mean & SE & Mean & SE & Mean & SE & \\
\hline \multicolumn{10}{|l|}{ Outcome $e^{b}$} \\
\hline Fair/poor physical health & 42.42 & 4.07 & $22.07^{a}$ & 1.75 & 38.58 & 3.44 & $25.94^{a}$ & 3.71 & 0.000 \\
\hline Past-year MDE & 13.15 & 1.76 & $8.87^{a}$ & 0.87 & $7.04^{a}$ & 1.08 & 9.52 & 2.22 & 0.033 \\
\hline \multicolumn{10}{|l|}{ Predictors } \\
\hline \multicolumn{10}{|l|}{ Perceived social mobility ${ }^{c}$} \\
\hline Test distribution & & & & & & & & & 0.000 \\
\hline Any downward mobility (-1to -9 ) & 53.64 & 3.11 & $42.12^{a}$ & 2.56 & $41.67^{a}$ & 2.29 & 52.78 & 2.68 & 0.010 \\
\hline Stable (0) [reference] & 21.03 & 2.46 & $10.96^{a}$ & 1.19 & 15.72 & 2.25 & 16.11 & 2.13 & 0.009 \\
\hline Any upward mobility (1-9) & 25.33 & 2.47 & $46.92^{a}$ & 2.68 & $42.61^{a}$ & 2.24 & 31.11 & 2.77 & 0.000 \\
\hline \multicolumn{10}{|l|}{ Perceived social status ${ }^{d}$ (origin) } \\
\hline Test distribution & & & & & & & & & 0.000 \\
\hline $1-3$ & 13.25 & 1.49 & $39.58^{a}$ & 2.26 & $25.94^{a}$ & 1.91 & $20.06^{a}$ & 2.04 & 0.000 \\
\hline $4-5$ & 22.56 & 3.12 & 14.53 & 1.70 & 28.45 & 2.01 & 22.47 & 2.47 & 0.000 \\
\hline $6-7$ & 25.39 & 3.16 & $7.22^{a}$ & 1.61 & 18.58 & 2.55 & 21.70 & 2.86 & 0.000 \\
\hline $8-10$ & 38.80 & 3.07 & 38.67 & 3.03 & $27.03^{a}$ & 2.05 & 35.77 & 3.25 & 0.019 \\
\hline \multicolumn{10}{|l|}{ Age } \\
\hline $18-34$ years & 23.76 & 3.59 & 18.96 & 1.95 & $56.18^{a}$ & 2.28 & $42.10^{a}$ & 3.05 & 0.000 \\
\hline $35-49$ years & 30.77 & 4.10 & 25.82 & 2.79 & 31.48 & 1.44 & 34.07 & 2.67 & 0.205 \\
\hline $50-64$ years & 28.96 & 3.95 & 28.89 & 2.51 & $9.82^{a}$ & 1.14 & $16.09^{a}$ & 2.17 & 0.000 \\
\hline 65 years or more & 16.51 & 6.40 & 26.33 & 2.56 & $2.52^{a}$ & 0.75 & 7.74 & 2.36 & 0.000 \\
\hline Female & 45.47 & 2.68 & 48.55 & 1.51 & 44.11 & 3.18 & $54.56^{a}$ & 2.65 & 0.076 \\
\hline \multicolumn{10}{|l|}{ Educational attainment } \\
\hline$<=11$ years & 44.08 & 5.57 & 33.95 & 2.40 & $67.71^{a}$ & 1.73 & 38.71 & 2.72 & 0.000 \\
\hline 12 years & 22.93 & 4.23 & 25.91 & 1.58 & 19.66 & 1.39 & 20.34 & 2.68 & 0.028 \\
\hline $13-15$ years & 19.87 & 2.40 & 18.20 & 2.32 & $8.26^{a}$ & 1.55 & $28.21^{a}$ & 2.93 & 0.000 \\
\hline$>=16$ years & 13.11 & 3.18 & $21.94^{a}$ & 2.55 & 4.37 & 1.12 & $12.74^{a}$ & 2.27 & 0.000 \\
\hline \multicolumn{10}{|l|}{ Household income } \\
\hline$\$ 0-14,999$ & 29.39 & 2.42 & 31.43 & 3.94 & 32.59 & 3.96 & 25.18 & 2.09 & 0.206 \\
\hline$\$ 15,000-34,999$ & 23.68 & 2.86 & 23.81 & 1.79 & $36.52^{a}$ & 2.50 & 28.68 & 3.38 & 0.001 \\
\hline$\$ 35,000-74,999$ & 29.87 & 2.96 & 25.06 & 2.27 & 21.90 & 2.93 & 31.26 & 3.13 & 0.115 \\
\hline$\$>=75,000$ & 17.05 & 3.12 & 19.70 & 3.44 & $8.99^{a}$ & 1.32 & 14.88 & 2.85 & 0.016 \\
\hline
\end{tabular}




\begin{tabular}{|c|c|c|c|c|c|c|c|c|c|}
\hline \multirow{3}{*}{ Sample size $(n)$} & \multirow{2}{*}{\multicolumn{2}{|c|}{$\begin{array}{l}\text { Puerto Ricans } \\
206\end{array}$}} & \multicolumn{2}{|c|}{ Cubans } & \multicolumn{2}{|c|}{ Mexicans } & \multicolumn{2}{|c|}{ Other Latinos } & \multirow{3}{*}{$\begin{array}{l}\text { Omnibus tests } \\
\text { p Value }\end{array}$} \\
\hline & & & \multicolumn{2}{|l|}{489} & \multicolumn{2}{|l|}{459} & \multicolumn{2}{|l|}{407} & \\
\hline & Mean & SE & Mean & SE & Mean & SE & Mean & SE & \\
\hline English proficiency & 49.67 & 3.88 & $30.70^{a}$ & 3.38 & $16.02^{a}$ & 2.21 & $32.62^{a}$ & 2.61 & 0.000 \\
\hline Year in US mainland ( $>5$ year) & 94.38 & 2.41 & $80.41^{a}$ & 4.83 & $81.64^{a}$ & 2.60 & $82.72^{a}$ & 2.57 & 0.004 \\
\hline \multicolumn{10}{|l|}{ Age arrive US } \\
\hline $0-6$ & 20.42 & 2.72 & $8.95^{a}$ & 1.72 & $6.89^{a}$ & 1.42 & $8.52^{a}$ & 1.47 & 0.001 \\
\hline $7-17$ & 31.02 & 2.60 & $15.66^{a}$ & 2.51 & 35.82 & 2.81 & $23.40^{a}$ & 2.19 & 0.000 \\
\hline $18+$ & 48.56 & 3.19 & $75.38^{a}$ & 3.11 & 57.29 & $2.39^{a}$ & $68.08^{a}$ & 2.16 & 0.000 \\
\hline Pre-migration psychiatric history & 16.89 & 2.65 & 17.02 & 1.25 & 11.69 & 1.29 & 12.07 & 1.87 & 0.022 \\
\hline Pre-migration physical health & 17.89 & 2.24 & $34.85^{a}$ & 3.31 & 16.15 & 2.52 & $26.26^{a}$ & 1.95 & 0.000 \\
\hline
\end{tabular}

Note: $\mathrm{MDE}=$ major depressive episode. $\mathrm{SSS}=$ subjective social status.

English-proficiency variable indicates good/excellent. A bolded p-value indicates a statistically significant Omnibus test.

${ }^{a}$ Indicates significant difference compared with Puerto Ricans $p<0.05$.

${ }^{b}$ Outcomes are age and gender adjusted by Latino subgroup.

${ }^{c}$ Perceived social mobility $=$ SSS in US- SSS if remained in country of origin.

$d$ There are 41 cases reported " 0 " in SSS of original, recoded to " 1 ". 


\section{Table 2}

Age and gender adjusted prevalence rates of fair/poor physical health and past-year major depressive episode among latino immigrants, NLAAS (2002-2003), $N=1561$.

\begin{tabular}{|c|c|c|c|c|c|c|c|c|}
\hline & \multicolumn{4}{|c|}{ Fair/poor health } & \multicolumn{4}{|l|}{ MDE } \\
\hline & $n$ & Mean & SE & $\boldsymbol{F}$ & $n$ & Mean & SE & $F$ \\
\hline \multicolumn{9}{|l|}{ Predictors } \\
\hline Perceived social mobility & & & & 0.65 & & & & 0.47 \\
\hline Any Downward Mobility (-1to -9$)$ & 726 & $33.4 \%$ & $2.6 \%$ & & 726 & $9.7 \%$ & $1.7 \%$ & \\
\hline Stable (0) [Reference] & 239 & $30.7 \%$ & $4.4 \%$ & & 239 & $6.3 \%$ & $1.9 \%$ & \\
\hline Any Upward Mobility (1 to 9) & 596 & $35.2 \%$ & $3.6 \%$ & & 596 & $8.0 \%$ & $1.7 \%$ & \\
\hline Perceived social status (origin) & & & & $5.27^{* *}$ & & & & 0.92 \\
\hline $1-3$ & 437 & $46.7 \%$ & $5.4 \%$ & & 437 & $9.0 \%$ & $1.8 \%$ & \\
\hline $4-5$ & 328 & $28.9 \%$ & $3.6 \%$ & & 328 & $7.5 \%$ & $1.3 \%$ & \\
\hline $6-7$ & 266 & $30.6 \%$ & $4.1 \%$ & & 266 & $9.0 \%$ & $2.1 \%$ & \\
\hline $8-10$ & 530 & $28.6 \%$ & $3.1 \%$ & & 530 & $8.6 \%$ & $1.9 \%$ & \\
\hline Educational attainment & & & & $24.13^{* * *}$ & & & & 0.80 \\
\hline$\unlhd 1$ years & 706 & $45.4 \%$ & $3.4 \%$ & & 706 & $9.2 \%$ & $1.6 \%$ & \\
\hline 12 years & 353 & $25.2 \%$ & $3.5 \%$ & & 353 & $9.3 \%$ & $1.7 \%$ & \\
\hline $13-15$ years & 283 & $15.2 \%$ & $2.9 \%$ & & 283 & $6.5 \%$ & $1.7 \%$ & \\
\hline$\geq 16$ years & 219 & $8.5 \%$ & $2.6 \%$ & & 219 & $5.7 \%$ & $2.3 \%$ & \\
\hline Household income & & & & $12.01^{* * *}$ & & & & 1.87 \\
\hline$\$ 0-14,999$ & 481 & $45.5 \%$ & $3.9 \%$ & & 481 & $11.8 \%$ & $2.7 \%$ & \\
\hline$\$ 15,000-34,999$ & 454 & $35.0 \%$ & $2.9 \%$ & & 454 & $8.2 \%$ & $1.6 \%$ & \\
\hline$\$ 35,000-74,999$ & 394 & $27.8 \%$ & $3.7 \%$ & & 394 & $6.4 \%$ & $1.8 \%$ & \\
\hline$\$ \geq 75,000$ & 232 & $12.1 \%$ & $3.0 \%$ & & 232 & $5.2 \%$ & $1.6 \%$ & \\
\hline English proficiency (good/excellent) & & & & $60.86^{* * *}$ & & & & 0.03 \\
\hline No & 1108 & $40.3 \%$ & $2.7 \%$ & & 1108 & $8.6 \%$ & $1.1 \%$ & \\
\hline Yes & 453 & $11.6 \%$ & $2.0 \%$ & & 453 & $8.2 \%$ & $2.2 \%$ & \\
\hline Year in US $(>5$ year $)$ & & & & $5.64^{*}$ & & & & 2.89 \\
\hline No & 247 & $24.9 \%$ & $3.6 \%$ & & 247 & $5.1 \%$ & $1.5 \%$ & \\
\hline Yes & 1314 & $35.1 \%$ & $2.6 \%$ & & 1314 & $9.1 \%$ & $1.1 \%$ & \\
\hline Age arrive US & & & & $14.00^{* * *}$ & & & & 2.34 \\
\hline $0-6$ & 154 & $14.4 \%$ & $2.5 \%$ & & 154 & $3.5 \%$ & $1.0 \%$ & \\
\hline $7-17$ & 393 & $25.5 \%$ & $2.1 \%$ & & 393 & $9.6 \%$ & $1.3 \%$ & \\
\hline $18+$ & 1014 & $39.1 \%$ & $3.7 \%$ & & 1014 & $8.7 \%$ & $1.4 \%$ & \\
\hline Pre-migration psychiatric history & & & & $17.34^{* *}$ & & & & $128.7^{* * *}$ \\
\hline No & 1337 & $31.0 \%$ & $2.2 \%$ & & 1337 & $4.1 \%$ & $0.9 \%$ & \\
\hline Yes & 224 & $50.4 \%$ & $5.7 \%$ & & 224 & $36.6 \%$ & $3.1 \%$ & \\
\hline Pre-migration physical health & & & & $11.50^{* *}$ & & & & $8.65^{* *}$ \\
\hline No & 1168 & $31.2 \%$ & $2.1 \%$ & & 1168 & $7.3 \%$ & $0.9 \%$ & \\
\hline
\end{tabular}




\begin{tabular}{|c|c|c|c|c|c|c|c|c|}
\hline & \multicolumn{4}{|c|}{ Fair/poor health } & \multicolumn{4}{|l|}{ MDE } \\
\hline & $n$ & Mean & SE & $F$ & $n$ & Mean & SE & $\boldsymbol{F}$ \\
\hline Yes & 393 & $42.6 \%$ & $4.5 \%$ & & 393 & $13.0 \%$ & $2.1 \%$ & \\
\hline
\end{tabular}

Note:

*** $\mathrm{p}<.0001$,

$* * \mathrm{p}<.01$.

* $\mathrm{p}<.05$;

$\mathrm{OR}=$ odds ratio; $\mathrm{CI}=$ confidence interval; Major Depressive Episode $=\mathrm{MDE}$. 
Table 3

Odds of past-year major depressive episode, NLAAS (2002-2003), $N=1561$.

\begin{tabular}{|c|c|c|c|c|c|c|}
\hline & \multicolumn{2}{|c|}{ Model $1\left(F=4.71^{* * * *}\right)$} & \multicolumn{2}{|c|}{ Model $2\left(F=19.18^{* * * *}\right)$} & \multicolumn{2}{|c|}{ Model $3\left(F=17.83^{\text {**** }}\right)$} \\
\hline & OR & $95 \% \mathrm{CI}$ & OR & $95 \% \mathrm{CI}$ & OR & $95 \% \mathrm{CI}$ \\
\hline \multicolumn{7}{|l|}{ Perceived social mobility } \\
\hline Any downward mobility (-1to -9 ) & $2.15^{*}$ & $(1.04-4.47)$ & $2.87^{*}$ & $(1.05-7.86)$ & $2.88^{*}$ & $(1.01-8.20)$ \\
\hline \multicolumn{7}{|l|}{ Stable (0) [Reference] } \\
\hline Any upward mobility (1-9) & 1.26 & $(0.40-3.93)$ & 1.55 & $(0.40-6.02)$ & 1.78 & $(0.44-7.10)$ \\
\hline \multicolumn{7}{|l|}{ Perceived social status (origin) } \\
\hline $1-3$ & 2.16 & $(0.75-6.26)$ & 2.43 & $(0.79-7.46)$ & 2.18 & $(0.70-6.78)$ \\
\hline $4-5$ & 1.80 & $(0.88-3.69)$ & 2.27 & $(0.99-5.24)$ & 2.23 & $(0.93-5.39)$ \\
\hline $6-7$ & 1.45 & $(0.71-2.97)$ & 1.78 & $(0.72-4.42)$ & 1.81 & $(0.68-4.78)$ \\
\hline \multicolumn{7}{|l|}{ 8-10 [Reference] } \\
\hline \multicolumn{7}{|l|}{ Age } \\
\hline \multicolumn{7}{|l|}{ 18-34 years [Reference] } \\
\hline $35-49$ years & 0.70 & $(0.43-1.15)$ & 0.73 & $(0.42-1.27)$ & 0.79 & $(0.45-1.40)$ \\
\hline 50-64 years & 1.24 & $(0.64-2.43)$ & 1.21 & $(0.58-2.52)$ & 1.31 & $(0.59-2.91)$ \\
\hline 65 years or more & 1.84 & $(0.64-5.29)$ & 2.09 & $(0.79-5.51)$ & 1.95 & $(0.76-4.98)$ \\
\hline Female & $2.37^{* * *}$ & $(1.50-3.74)$ & $2.20 * *$ & $(1.29-3.75)$ & $2.04^{* *}$ & $(1.24-3.36)$ \\
\hline \multicolumn{7}{|l|}{ Educational attainment } \\
\hline \multicolumn{7}{|l|}{$<=11$ years $[$ Reference $]$} \\
\hline 12 years & & & & & 1.22 & $(0.70-2.13)$ \\
\hline $13-15$ years & & & & & 1.16 & $(0.54-2.50)$ \\
\hline$>=16$ years & & & & & 1.14 & $(0.25-5.18)$ \\
\hline \multicolumn{7}{|l|}{ Household income } \\
\hline \multicolumn{7}{|l|}{ \$0-14,999 [Reference] } \\
\hline$\$ 15,000-34,999$ & & & & & 0.81 & $(0.45-1.46)$ \\
\hline$\$ 35,000-74,999$ & & & & & $0.45^{*}$ & $(0.24-0.84)$ \\
\hline$\$>=75,000$ & & & & & 0.54 & $(0.15-1.92)$ \\
\hline \multicolumn{7}{|l|}{ Sub-ethnicity } \\
\hline \multicolumn{7}{|l|}{ Puerto Ricans [Reference] } \\
\hline Cubans & 0.59 & $(0.35-1.01)$ & 0.58 & $(0.29-1.16)$ & 0.57 & $(0.29-1.11)$ \\
\hline Mexicans & $0.51^{*}$ & $(0.26-0.98)$ & 0.56 & $(0.30-1.08)$ & 0.58 & $(0.28-1.20)$ \\
\hline Other Latinos & 0.61 & $(0.30-1.25)$ & 0.76 & $(0.35-1.64)$ & 0.76 & $(0.33-1.76)$ \\
\hline English proficiency (good/excellent) & 1.08 & $(0.40-2.92)$ & 0.99 & $(0.31-3.19)$ & 1.10 & $(0.29-4.23)$ \\
\hline Year in US ( $>5$ year) & 1.85 & $(0.95-3.61)$ & $2.41^{*}$ & $(1.19-4.88)$ & $2.52^{*}$ & $(1.20-5.31)$ \\
\hline \multicolumn{7}{|l|}{ Age arrive US } \\
\hline \multicolumn{7}{|l|}{$0-6$ [Reference $]$} \\
\hline $7-17$ & $3.33^{*}$ & $(1.23-9.01)$ & 1.50 & $(0.49-4.61)$ & 1.58 & $(0.47-5.32)$ \\
\hline $18+$ & 2.28 & $(0.68-7.62)$ & 0.73 & $(0.18-2.99)$ & 0.78 & $(0.17-3.64)$ \\
\hline
\end{tabular}




\begin{tabular}{|c|c|c|c|c|c|c|}
\hline & \multicolumn{2}{|c|}{ Model $1\left(F=4.71^{* * * *}\right)$} & \multicolumn{2}{|c|}{ Model $2\left(F=19.18^{* * *}\right)$} & \multicolumn{2}{|c|}{ Model $3\left(F=17.83^{* * *}\right)$} \\
\hline & OR & $95 \%$ CI & OR & $95 \%$ CI & OR & $95 \%$ CI \\
\hline Pre-migration psychiatric history & & & $19.2^{* * *}$ & $(11.3-32.8)$ & $20.2^{* * *}$ & $(11.5-35.4)$ \\
\hline${ }^{* * *} \mathrm{p}<0.001$ & & & & & & \\
\hline $\begin{array}{l}* * \\
\quad \mathrm{p}<0.01 \\
* \mathrm{p}<0.05 .\end{array}$ & & & & & & \\
\hline
\end{tabular}




\section{Table 4}

Final model on relationship between perceived social mobility and past-year MDE including interaction terms, NLAAS (2002-2003; $n=1561)$.

\begin{tabular}{|c|c|c|}
\hline & OR & $95 \% \mathrm{CI}$ \\
\hline \multicolumn{3}{|l|}{ Sub-ethnicity } \\
\hline \multicolumn{3}{|l|}{ Puerto Ricans [Reference] } \\
\hline Cubans & 2.98 & $(0.86-10.3)$ \\
\hline Mexicans & 0.46 & $(0.058-3.71)$ \\
\hline Other Latinos & 0.42 & $(0.12-1.42)$ \\
\hline \multicolumn{3}{|l|}{ Interactions } \\
\hline$[\mathrm{DM}]^{*}$ Puerto Ricans vs. [0] ${ }^{*}$ Puerto Ricans & $3.16^{*}$ & $(1.03-9.75)$ \\
\hline$[\mathrm{DM}]^{*}$ Cuban vs. $[0]^{*}$ Cuban & 0.38 & $(0.11-1.30)$ \\
\hline$[\mathrm{DM}]^{*}$ Mexicans vs. $[0]^{*}$ Mexican & 3.85 & $(0.57-26.2)$ \\
\hline$[\mathrm{DM}]^{*}$ Other Latinos vs. $[0]^{*}$ Other Latinos & $3.94 *$ & $(1.14-13.7)$ \\
\hline$[\mathrm{UM}]^{*}$ Puerto Ricans vs. [0] ${ }^{*}$ Puerto Ricans & 0.74 & $(0.18-3.09)$ \\
\hline$[\mathrm{UM}]^{*}$ Cuban vs. $[0]^{*}$ Cuban & $0.24^{* *}$ & $(0.10-0.57)$ \\
\hline$[\mathrm{UM}]^{*}$ Mexicans vs. $[0]^{*}$ Mexican & 1.85 & $(0.14-24.4)$ \\
\hline$[\mathrm{UM}]^{*}$ Other Latinos vs. $[0]^{*}$ Other Latinos & $4.74^{*}$ & $(1.03-21.9)$ \\
\hline \multicolumn{3}{|l|}{$\mathrm{p}<0.001$} \\
\hline \multicolumn{3}{|l|}{$\mathrm{p}<0.01$} \\
\hline $\mathrm{p}<0.05$ & & \\
\hline
\end{tabular}

Note: $\mathrm{OR}=$ odds ratio; $\mathrm{CI}=$ confidence interval; $\mathrm{DM}=$ downward mobility; $\mathrm{UP}=$ upward mobility; $[0]=$ stable.

Model adjusts for age, gender, English proficiency, age at migration, perceived social status (origin), year in U.S., pre-migration psychiatric disorder, household income, and educational attainment. 
Table 5

Odds of self-rated fair/poor physical health, NLAAS (2002-2003), $N=1561$.

\begin{tabular}{|c|c|c|c|c|c|c|}
\hline & \multicolumn{2}{|c|}{ Model $1\left(F=12.14^{* * * *}\right)$} & \multicolumn{2}{|c|}{ Model $2\left(F=11.92^{* * * *}\right)$} & \multicolumn{2}{|c|}{ Model $3\left(F=11.42^{* * * *}\right)$} \\
\hline & OR & $95 \% \mathrm{CI}$ & OR & $95 \% \mathrm{CI}$ & OR & $95 \% \mathrm{CI}$ \\
\hline \multicolumn{7}{|l|}{ Perceived social mobility } \\
\hline Any downward mobility (-1to -9 ) & $2.04^{* *}$ & $(1.22-3.39)$ & $1.95^{* *}$ & $(1.19-3.21)$ & $1.99^{* *}$ & $(1.21-3.27)$ \\
\hline \multicolumn{7}{|l|}{ Stable (0) [Reference] } \\
\hline Any upward mobility (1-9) & 0.76 & $(0.50-1.15)$ & 0.74 & $(0.49-1.13)$ & 0.86 & $(0.57-1.30)$ \\
\hline \multicolumn{7}{|l|}{ Perceived social status (origin) } \\
\hline $1-3$ & $3.90^{* * *}$ & $(1.96-7.76)$ & $3.92^{* * *}$ & $(1.99-7.71)$ & $3.00^{* *}$ & $(1.58-5.71)$ \\
\hline $4-5$ & 1.32 & $(0.68-2.58)$ & 1.38 & $(0.70-2.73)$ & 1.19 & $(0.63-2.24)$ \\
\hline $6-7$ & 1.26 & $(0.79-2.00)$ & 1.28 & $(0.78-2.10)$ & 1.24 & $(0.78-1.98)$ \\
\hline \multicolumn{7}{|l|}{$8-10[$ Reference $]$} \\
\hline \multicolumn{7}{|l|}{ Age } \\
\hline \multicolumn{7}{|l|}{ 18-34 years [Reference] } \\
\hline $35-49$ years & 1.15 & $(0.68-1.97)$ & 1.17 & $(0.69-1.99)$ & 1.22 & $(0.71-2.11)$ \\
\hline 50-64 years & $1.93^{* * *}$ & $(1.38-2.69)$ & $1.92^{* * *}$ & $(1.38-2.68)$ & $1.87^{* * *}$ & $(1.32-2.65)$ \\
\hline 65 years or more & $3.48^{* * *}$ & $(1.72-7.01)$ & $3.51^{* * *}$ & $(1.74-7.08)$ & $2.90^{* *}$ & $(1.46-5.79)$ \\
\hline Female & $1.42^{* *}$ & $(1.09-1.85)$ & $1.36^{*}$ & $(1.05-1.78)$ & $1.33^{*}$ & $(1.02-1.73)$ \\
\hline \multicolumn{7}{|l|}{ Educational attainment } \\
\hline \multicolumn{7}{|l|}{$<=11$ years [Reference $]$} \\
\hline 12 years & & & & & 0.72 & $(0.49-1.07)$ \\
\hline $13-15$ years & & & & & $0.46^{* * *}$ & $(0.29-0.71)$ \\
\hline$>=16$ years & & & & & $0.45^{*}$ & $(0.21-0.96)$ \\
\hline \multicolumn{7}{|l|}{ Household income } \\
\hline \multicolumn{7}{|l|}{$\$ 0-14,999$ [Reference] } \\
\hline$\$ 15,000-34,999$ & & & & & 0.74 & $(0.55-1.01)$ \\
\hline$\$ 35,000-74,999$ & & & & & 0.71 & $(0.45-1.11)$ \\
\hline$\$>=75,000$ & & & & & $0.44^{* *}$ & $(0.24-0.79)$ \\
\hline \multicolumn{7}{|l|}{ Sub-ethnicity } \\
\hline \multicolumn{7}{|l|}{ Puerto Ricans [Reference] } \\
\hline Cubans & $0.24^{* * *}$ & $(0.16-0.38)$ & $0.23^{* * *}$ & $(0.15-0.37)$ & $0.27^{* * *}$ & $(0.17-0.43)$ \\
\hline Mexicans & 0.73 & $(0.45-1.17)$ & 0.75 & $(0.46-1.22)$ & 0.67 & $(0.41-1.10)$ \\
\hline Other Latinos & $0.34^{* * *}$ & $(0.20-0.57)$ & $0.34^{* * *}$ & $(0.20-0.57)$ & $0.37^{* * *}$ & $(0.22-0.62)$ \\
\hline English proficiency (good/excellent) & $0.24^{* * *}$ & $(0.14-0.40)$ & $0.25^{* * *}$ & $(0.14-0.42)$ & $0.35^{* *}$ & $(0.19-0.65)$ \\
\hline Year in US $(>5$ year $)$ & 1.37 & $(0.91-2.05)$ & 1.45 & $(0.95-2.23)$ & 1.56 & $(0.99-2.46)$ \\
\hline \multicolumn{7}{|l|}{ Age arrive US } \\
\hline \multicolumn{7}{|l|}{$0-6$ [Reference] } \\
\hline $7-17$ & 0.73 & $(0.43-1.21)$ & 0.69 & $(0.41-1.16)$ & 0.68 & $(0.41-1.12)$ \\
\hline $18+$ & 0.89 & $(0.50-1.58)$ & 0.80 & $(0.46-1.42)$ & 0.85 & $(0.50-1.44)$ \\
\hline
\end{tabular}




\begin{tabular}{|c|c|c|c|c|c|c|}
\hline & \multicolumn{2}{|c|}{ Model $1\left(F=12.14^{* * *}\right)$} & \multicolumn{2}{|c|}{ Model $2\left(F=11.92^{* * *}\right)$} & \multicolumn{2}{|c|}{ Model $3\left(F=11.42^{* * * *}\right)$} \\
\hline & OR & $95 \%$ CI & OR & $95 \%$ CI & OR & $95 \%$ CI \\
\hline Pre-migration physical health & & & $1.59^{*}$ & $(1.07-2.34)$ & $1.53^{*}$ & $(1.03-2.29)$ \\
\hline \multicolumn{7}{|l|}{$* * * * 0.001$} \\
\hline \multicolumn{7}{|l|}{${ }^{* *}<0.01$} \\
\hline$*^{*}<0.05$. & & & & & & \\
\hline
\end{tabular}

